\title{
Assessment of coal pillar stability using principal component analysis and stepwise selection and elimination
}

\begin{abstract}
Prediction of pillar stability is one of the most critical tasks in underground mining industries. This pillar stability analysis requires many input parameters and some of them are difficult to be determined. Various statistical based analysis is presented in literature for assessing pillar stability successfully. In the present work, the data from three mines had been to determine the factor of safety. A total of 63 pillar cases had been collected from the mines. Principal component analysis (PCA) and Stepwise selection and elimination (SSE) models were developed by using multi variate linear regression (MLR) on 45 data sets and subsequently the proposed models were validated on 18 different data sets. The value of coefficient of determination (R2) is 0.86 and 0.84 for PCA and SSE respectively. The root mean square error for PCA and SSE are found to be 0.112 and 0.123 respectively. On validation of the proposed model developed by PCA and SSE, the PCA model provided a better validation results. Hence, PCA is recommended for modelling pillar stability.
\end{abstract}

Keywords: Pillar stability, factor of safety, PCA, SSE

\subsection{Introduction}

$\mathrm{M}$ ining is one of the foremost practiced industries in the world. The two general forms of mining practice are opencast mining and underground mining. The two basic techniques for underground mining incorporate longwall mining and bord and pillar technique for mining. The technique for the foremost part common within the Indian underground mines is the bord and pillar technique for mining in the light of the actual fact that of its history and ease of activity in mining engineering, the deterministic techniques are generally utilized for mine design. For occasion, the safety factor is often presented as a quantitative investigation approach for pillars or slope stability design, in the long run,

Blind peer reviews carried out

Messrs. Brijesh Kumar, Punit Paurush, Sanjay K. Sharma, Gauri S. Prasad Singh, Department of Mining Engineering, Indian Institute of Technology (BHU), Varanasi, India. E-mail: brijeshkr.rs.min15@ itbhu.ac.in / punitp.rs.min15@itbhu.ac.in / sksharma.min@iitbhu.ac.in / gspsingh.min@iitbhu.ac.in large scale underground mining, many goafs are one of all the foremost important factors that endanger mine production safety, and pillars are main structures of the column that affected the steadiness of goafs. The instability of a pillar will cause the collapse of the roof in goaf area, leading to an oversized number of causalities, and heavy property losses $[1,2,3]$.

The importance of pillar stability has given a sizable amount of publications in the past few years on various aspects of pillar stability and plenty of valuables approaches are applied to urge a decent amount of data in gaining understanding about pillar stability. Basically, methods are applied by researchers in the past few decades and are categorized as empirical methods [4,5] and numerical simulation $[6,7,8]$. Normally strength determination is performed by empirical methods $[9,10,11]$; here as pillar stress is difficult to see in underground mines, a factor of safety (Fos) of a pillar, which is defined as the ratio of pillar strength to the pillar load. Which is employed to estimate pillar stability $[6,7,8,9,10,11,12]$. Generally, when Fos $>1$ then we will say pillar is stable, if Fos $<1$ we will conclude it with unstable pillar $[12,13,14]$. But in some cases pillars also are collapsed with Fos $>1$. These are exceptional ones. As mining industries are expanding plenty of numerical simulation technology and numerical simulation softwares are introduced and are often used for understanding pillar stability. A lot of models and pillar designs are formulated by researchers by combining the simulation software and technology for instance pillar design by [6] using FLAC and Monte Carlo. The numerical simulation model is ready by [15] using FLAC 3D. The deformation and failure process of a pillar in nature of the condition was analyzed by [7] using UDEC software. This sort of study had improved the knowledge in understanding the pillar stability condition. But these methods also contain some disadvantages due to which this needs to replace with some new approaches. As pillar stability is laid low with secured parameters it is difficult for these methods to accumulate proper influence of uncertainty. Secondly, due to the non-linear behaviour of pillars with high stress in underground working, these methods do not seem to be suitable. 
Theoretically, Fos $>1$ is a stable pillar but in some cases, the pillar fails after having Fos $>1$ so the boundary of pillar stability is indefinite and unknown. According to the data of the past few years mining methods and intelligence evaluation models/machine learning has been successfully applied to pillar stability analysis and also given desirable outcome with the increasing availability of pillar parameters. In pillar stability prediction supported uncertainty of data and model [16] developed a probabilistic model. Logistic regression was introduced by [14], [17] proposed a model for predicting the steadiness of pillars combined with random field theory and Monte Carlo methods [18] applied and supervised learning methods, like Fischer discriminant analysis support vector machines SVM, Random forest RF, linear discriminant analysis (LDA) and multilayer perceptron neural performance of the algorithms by comparing the result. [19] used the intelligence algorithms to boost the prediction performance of pillar stability using RF. The above-mentioned algorithms are helpful in understanding pillar stability but each of them has its advantages and limitations [18, 19, 20,21]. In the past few years, a number of researchers have used particular parameters to understand pillar stability, as an example, [22] used pillar width and depth of mine to understand pillar stability analysis of [23], showed that pillar width, mining depth, and entry width have a most significant influence on pillar stability [18] and [14] developed their model by using the ratio of pillar width to pillar height and pillar strength to pillar stress.

In the present study, we have taken more than six parameters as an input parameter, which includes pillar height, pillar width, entry width, pillar strength, pillar load, and their ratios affecting factor of safety (FoS). All the parameters are here used to understand their importance according to affectivity on FoS in pillar stability. Although, the stability of pillars in underground mines is affected by many factors like the pillar load, the dimensions of the pillar, geological structures, etc. In the present work, principal component analysis (PCA) and stepwise selection and elimination (SSE) statistical tools were applied to identify the foremost affecting parameters in pillar stability in underground coal mines. PCA and SSE based model were developed and validation of the proposed models are done on the another set of data sets. On the other hand, the comparative study on the basis of PCA and SSE has been carried out to develop the more authentic predictor equation.

\subsection{Database}

Total of 63 pillar cases from three underground coal mines (MINE A, B and C) were taken in which 45 pillar cases for analysis and 18 pillar cases for validation of underground coal mines were used, whose statistical description is given in Table 1. Mine A is located in South Eastern Coalfields (SECL) Chhattisgarh. In mine (A) the dolerite sill (40m to $130 \mathrm{~m})$ lies within the upper section of Barakar and thus over lies the
Table 1: Datasets Statistical Details.

\begin{tabular}{lcccc}
\hline $\begin{array}{l}\text { Input } \\
\text { Parameters }\end{array}$ & $\mathrm{N}$ & Minimum & Maximum & Mean \\
\hline $\mathrm{D}$ & 45 & 42 & 300 & 133.20 \\
$\mathrm{~W}$ & 45 & 25.0 & 26.0 & 25.133 \\
$\mathrm{~B}$ & 45 & 3.5 & 4.8 & 4.364 \\
$\mathrm{H}$ & 45 & 2 & 4 & 2.62 \\
$\mathrm{~W} / \mathrm{H}$ & 45 & 7.1429 & 14.8571 & 9.764017 \\
$\mathrm{~B} / \mathrm{W}$ & 45 & .1 & .2 & .184 \\
$\mathrm{~B} / \mathrm{H}$ & 45 & 1.1 & 2.2 & 1.678 \\
$\mathrm{UCS}$ & 45 & 18 & 85 & 47.24 \\
$\mathrm{PL}$ & 45 & 2.2 & 12.5 & 7.484 \\
$\mathrm{H} / 250$ & 45 & .007 & .014 & .01082 \\
$\mathrm{PS}$ & 45 & 13.1167 & 23.8712 & 17.751030 \\
FoS & 45 & 1.3367 & 6.9088 & 2.934137 \\
Valid N & & & & \\
(listwise) & 45 & & & \\
\hline
\end{tabular}

middle section containing the important coal seam and its floor strata was covered with shally sandstone. Mine B was located in Singareni Collieries Company Limited (SCCL) whose nature of roof strata was $5.7 \mathrm{~m}$ medium grained sandstone and its nature of floor strata was $0.3 \mathrm{~m}$ carb. Sandstone. And mine C is located in Srirampur Area of the SCCL in the Northern part of the Godavari Valley Coalfield on its western basin. $7-9 \mathrm{~m}$ medium to fine grained sandstone and floor strata consists of fine to medium grained sandstone lie on the upper section.

\subsection{Methodology}

\section{BACKGROUND}

One of the foremost unmistakable styles of mishaps in underground mining is the collapse of the pillar, a factor of safety is employed to point pillar stability. Pre-estimation of a safety factor can give an adequate and stable idea of the pillar design. it is the ratio of the strength of the pillar to the stress of the pillar and mathematically expressed as eq.1:

$$
\mathrm{FoS}=\frac{\text { Pillar strength }}{\text { Pillar load }}=\frac{P S}{P L}
$$

Where FoS is factor of safety.

\section{Pillar Strength}

The pillar's strength represents the consistency of the materials and therefore the distribution of stresses within the pillar, it is important to look at the variable that affects the pillar's stress distribution. The vertical and horizontal components of the stress vector at the contact between the pillar and also the surrounding strata are likely to be the foremost important factors [24]. The distribution of those components and their magnitude are strongly influenced by the friction and cohesion of the contact plane by the deformation characteristics of the pillar material and surrounding strata. The strength of the pillar tends to extend 
within the ratio of width ' $\mathrm{W}$ ' to height ' $\mathrm{H}$ ' because of the lateral containment of the pillar by the contact stress lateral components. Estimation of pillar strength is kind of challenging infield thanks to the dearth of the larger size of testing equipment. However, the sample size has been broadly accepted and includes a major impact on the strength of coal samples [25] [26]. A general equation for determination of pillar strength (PS) is given as eq.2:

$$
P S=k \cdot W^{\alpha} \cdot H^{\alpha}
$$

Where, $W$ is pillar width, $H$ is the pillar height, $\alpha$ and $\beta$ are constants and $k$ is constant represent strength of coal material.

The strength of pillars in Table 1, were estimated by equation proposed by [27] as eq.3:

$$
P S=0.27 \sigma_{c} H^{-0.36}+\left(\frac{D}{250}+1\right)\left(\frac{W}{H}-1\right)
$$

Where $P S$ is pillar strength in $\mathrm{MPa}, H$ is pillar height in $\mathrm{m}$, $\sigma_{c}$ is uniaxial compressive strength in $\mathrm{MPa}, W$ is pillar width in $\mathrm{m}$ and $D$ is depth of cover in $\mathrm{m}$.

\section{Pillar Stress}

Estimation of stress on a pillar is one of the difficult tasks to perform in pillar design. When required pillar layouts are consisting of equally spaced and more or less same sized pillars. The Tributary area method will be applied simply to work out the pillar stress. This method involves that the total load of the overburden is equally distributed over all pillars. Though it refuses the actual fact that the quantity of load may be transferred to barrier pillars or solid abutment, which depends on the stiffness of the pillars and surrounding overburden, still it is an acceptable and quite developed method for correct stable pillar design [28]. The overburden of coal bearing strata is taken as $0.025 \mathrm{MN} / \mathrm{m}^{3}$ and pillar load is represented in the form of eq. 4 .

$$
P L=0.025 H \frac{(W+B)^{2}}{W^{2}}
$$

Where $P L$ is pillar stress (pillar load) in $\mathrm{MPa}, B$ is gallery width in $\mathrm{m}$.

\subsection{ReSEARCH DESIGN}

The PCA and SSE techniques have been employed to determine the parameters affecting FoS. Furthermore, multi variate linear regression (MLR) model have been developed to determine the coefficient of determination (R2) for both techniques.

\section{PCA}

Principal component analysis (PCA) is a technique for reducing the dimensionality of such datasets, increasing interpretability but at the same time minimizing information loss. It does so by creating new uncorrelated variables that successively maximize variance. Finding such new variables, the principal components, reduces to solving an eigenvalue/ eigenvector problem, and the new variables are defined by the dataset at hand, not a priori, hence making PCA an adaptive data analysis technique.

This means that 'preserving as much variability as possible' translates into finding new variables that are linear functions of those in the original dataset, that successively maximize variance, and that are uncorrelated with each other. Finding such new variables, the principal components (PCs), reduces to solving an eigenvalue/eigenvector problem. The earliest literature on PCA dates from [29] and [30], but it was not until electronic computers became widely available decades later that it was computationally feasible to use it on datasets that were not trivially small. Since then its use has burgeoned and a large number of variants have been developed.

SSE

Stepwise selection and elimination (SSE) is a blend of the forward and reverses choice strategies. It was extremely well known at one time. Stepwise regression is an adjustment of the forward determination so that after each progression wherein a variable was added, all variables in the model are verified whether their criticalness has been diminished beneath the predetermined tolerance level. On the off chance that a non-significance variable is discovered, it is taken out from the model. Stepwise regression requires two essentialness levels: one for adding variables and one for eliminating variables. The cutoff likelihood for adding variables should be not exactly the cutoff likelihood for eliminating variables so that the technique does not get into a limitless circle.

MLR

Multivariate linear regression is a strategy used to quantify how much more than one independent variable (predicators) and more than one variable (responses), are linearly related. The technique is comprehensively used to anticipate the conduct of the response variables related to changes in the predictor variables when a desired degree of connection has been set up. To develop the model for both PCA and SSE, the MLR equation has been used.

$$
\bar{Y}=A+\left(B_{1} X_{1}\right)+\left(B_{2} X_{2}\right)+\ldots+\left(B_{n} X_{n}\right)
$$

Where $\bar{Y}$ is predicted value of $Y, A$ is intercept and $B$ is regression coefficient.

\subsection{Result and discussion}

The basis descriptive statistics of the recorded data are illustrated in Table 1. We have employed the PCA and SSE followed by MLR technique for prediction of pillar design parameters affecting FoS.

Further, the results and discussion is illustrated in following parts:

\subsection{Principal Component Analysis}

PCA is a technique which helps to identify the 
TABLE 2: TotAL VARIANCE EXPLAINED

\begin{tabular}{|c|c|c|c|c|c|c|}
\hline \multirow[t]{2}{*}{ Component } & \multicolumn{3}{|c|}{ Initial eigenvalues } & \multicolumn{3}{|c|}{ Extraction sums of squared loadings } \\
\hline & Total & $\%$ of Variance & Cumulative $\%$ & Total & $\%$ of Variance & Cumulative $\%$ \\
\hline 1 & 5.462 & 49.658 & 49.658 & 5.462 & 49.658 & 49.658 \\
\hline 2 & 3.141 & 28.558 & 78.215 & 3.141 & 28.558 & 78.215 \\
\hline 3 & 1.309 & 11.899 & 90.114 & 1.309 & 11.899 & 90.114 \\
\hline 4 & .516 & 4.689 & 94.803 & & & \\
\hline 5 & .228 & 2.076 & 96.879 & & & \\
\hline 6 & .200 & 1.822 & 98.701 & & & \\
\hline 7 & .116 & 1.059 & 99.760 & & & \\
\hline 8 & .016 & .149 & 99.909 & & & \\
\hline 9 & .005 & .048 & 99.957 & & & \\
\hline 10 & .004 & .037 & 99.994 & & & \\
\hline 11 & .001 & .006 & 100.000 & & & \\
\hline
\end{tabular}

components that is important in prediction of the desired output. The variance obtained with the help of PCA is 90.114 , which indicates the excellent variability in the input parameters as is shown in Table 2.

The components derived by the PCA is illustrated in Table 3. By Table 3, it is clear that the PCA has derived three principal components group for the data used in the study. With this component matrix, we have selected that input parameters which have highest correlation with the output in all the three components.

We have found that seven parameters, namely, W/H, B, $\mathrm{PL}, \mathrm{PS}, \mathrm{D}, \mathrm{H}, \mathrm{B} / \mathrm{H}$ have selected with higher degree of correlation from the component matrix as indicated in Table 3.

MLR have been employed on all the selected seven principal components and the results in the form of model summary has been given in Table 4 . The value of $\mathrm{R}^{2}$ obtained for this is 0.891 , but on the analysis, it is found that variance inflation factor $>10$ for the results obtained with seven components. It shows that the multi-collinearity exists among all the selected input parameters, so this model is rejected.

Table 3: The Components matrix

\begin{tabular}{lrrr}
\hline & \multicolumn{3}{c}{ Component } \\
\cline { 2 - 4 } & \multicolumn{1}{c}{1} & \multicolumn{1}{c}{3} \\
\hline Depth & .519 & .781 & .242 \\
W & -.793 & -.076 & .282 \\
B & .993 & .374 & -.454 \\
H & .800 & -.416 & .655 \\
W/H & -.967 & .219 & -.045 \\
B/W & .731 & .121 & -.529 \\
B/H & -.706 & .551 & -.606 \\
UCS & .725 & .643 & .050 \\
PL & .916 & .711 & .452 \\
H/250 & .442 & -.231 & .148 \\
PS & -.225 & .935 & -.059 \\
\hline
\end{tabular}

TABle 4: Model SUMmary with MC

\begin{tabular}{lllll}
\hline Model & $\mathrm{R}$ & $\mathrm{R}$ square & $\begin{array}{l}\text { Adjusted } \\
\mathrm{R} \text { square }\end{array}$ & $\begin{array}{l}\text { Std. error of } \\
\text { the estimate }\end{array}$ \\
\hline 1 & $.944 \mathrm{a}$ & .891 & .870 & .5533933 \\
\hline a. Predictors: (Constant), $\mathrm{PL}, \mathrm{B}, \mathrm{B} / \mathrm{H}, \mathrm{PS}, \mathrm{H}, \mathrm{W} / \mathrm{H}$, depth
\end{tabular}

To remove the multi-collinearity, we have minimized the values of VIF and found it to be under the limited value 10 . After removal of multi-collinearity, we have found four parameters namely, PS, H, B/H and PL. The MLR have been employed with the four parameters and the value of R2 obtained is 0.858 , the model summary is illustrated in Table 5. It shows the results without having any multi-collinearity among the parameters with 0.000 significance and very high value of F-statistics.

To derive the model for PCA, we have used the unstandardized coefficients derived with the help of PCA analysis as indicated in Table 6.

To propose the model, the $\beta$ values have been used and the equation formed has been written as eq.6:

$$
\begin{aligned}
& F O S=2.181+P S \times(0.135)+H \times(0.601) \\
& +\frac{B}{H} \times(0.308)-P L(0.502)
\end{aligned}
$$

\subsection{SteP-WiSE SELECTION AND ELIMINATION}

In the SSE technique, we have selected and eliminated the parameters based on the bi-variate Pearson's correlation coefficient and their significant values as shown in Table 7.

On analysing, we have found seven components having effect on FoS. On selected seven components, namely, B/H, $\mathrm{D}, \mathrm{B}, \mathrm{UCS}$ and H/250, we have employed MLR to obtain the value of $\mathrm{R}^{2}$ and it is found to be 0.871 as indicated in Table 8 . It is also found that these five components are having multicollinearity among themselves, so this model is rejected. Furthermore, we have removed the multi-collinearity and derived the new model having no any multi-collinearity. 
TABle 5: Model SUMmary without MC

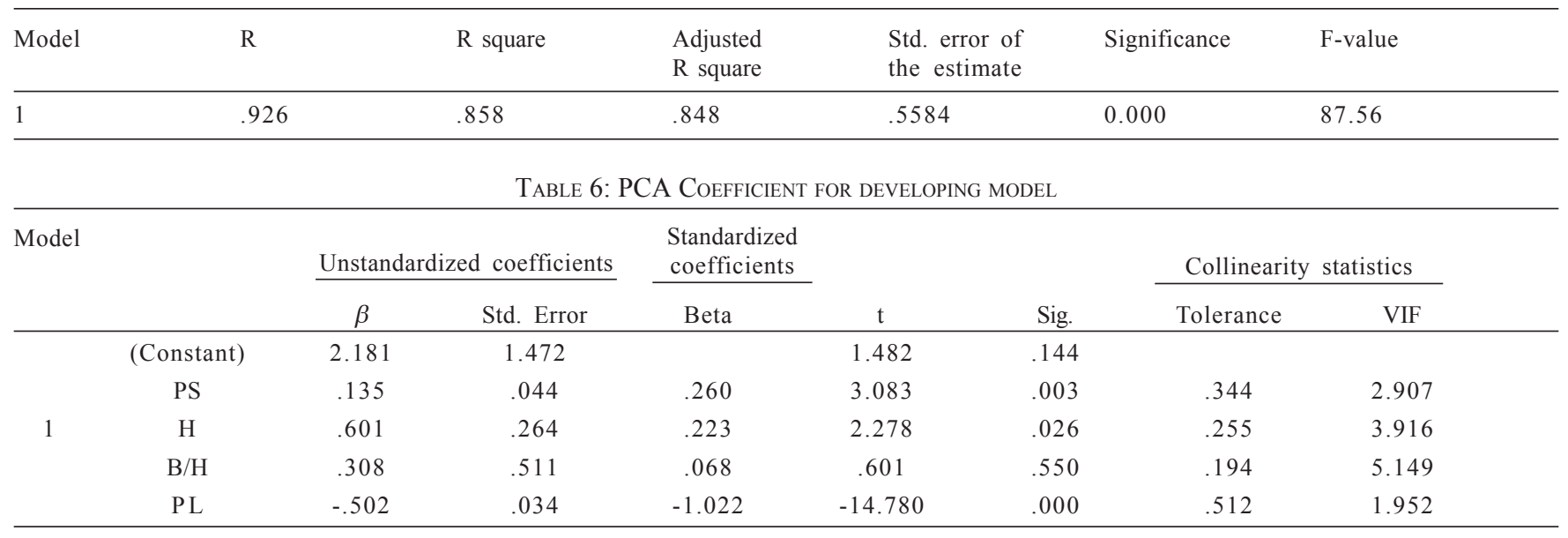

TABle 7: Correlation MATRIX

\begin{tabular}{llll}
\hline Parameter & $\begin{array}{l}\text { Pearson } \\
\text { correlation }\end{array}$ & Significance & $\begin{array}{l}\text { Number of } \\
\text { datasets }\end{array}$ \\
\hline D & 0.565 & 0.000 & 45 \\
W & 0.102 & 0.504 & 45 \\
B & 0.221 & 0.004 & 45 \\
H & 0.79 & 0.608 & 45 \\
W/H & 0.103 & 0.502 & 45 \\
B/W & 0.205 & 0.177 & 45 \\
B/H & 0.289 & 0.005 & 45 \\
UCS & 0.895 & 0.000 & 45 \\
PL & 0.49 & 0.750 & 45 \\
H/250 & 0.395 & 0.017 & 45 \\
PS & 0.149 & 0.650 & 45 \\
\hline
\end{tabular}

TABle 8: Model SUMmary WITH MC

\begin{tabular}{|c|c|c|c|c|}
\hline Model & $\mathrm{R}$ & $\mathrm{R}$ square & $\begin{array}{l}\text { Adjusted } \\
\mathrm{R} \text { square }\end{array}$ & $\begin{array}{l}\text { Std. Error of } \\
\text { the estimate }\end{array}$ \\
\hline 1 & $.934 a$ & .871 & .855 & .5844869 \\
\hline
\end{tabular}

After removal of multi-collinearity, the four parameters namely, D, UCS, B and B/H have been selected. The MLR have been employed on these four parameters and the results are illustrated in Table 9. The value of $\mathrm{R}^{2}$ obtained is 0.846 with 0.000 significance and high value of F-statistics.

To derive the model for SSE, we have used the unstandardized coefficients as indicated in Table 10.

The $\beta$ values have been used to derive the equation, which is given as below as eq 7 :

$$
\begin{aligned}
& F o S=-8.212-D \times(0.022)+U C S \times(0.020) \\
& +B \times(2.870)+\frac{B}{H} \times(0.399)
\end{aligned}
$$

\subsection{Validation results}

For the validation of the proposed model by PCA and SSE as indicated in eq. 6 and 7, we have used another 18 data sets the summary is illustrated in Table 11. The values of FoS derived with the proposed models are also indicated in Table 11.

\begin{tabular}{|c|c|c|c|c|c|c|}
\hline Model & $\mathrm{R}$ & $\mathrm{R}$ square & $\begin{array}{l}\text { Adjusted } \\
\mathrm{R} \text { square }\end{array}$ & $\begin{array}{l}\text { Std. error of } \\
\text { the estimate }\end{array}$ & Significance & F-value \\
\hline 1 & .920 & .846 & .818 & .5929 & 0.000 & 63.724 \\
\hline
\end{tabular}

Table 9: Model summary without MC.

\begin{tabular}{|c|c|c|c|c|c|c|c|c|}
\hline \multirow[t]{2}{*}{ Model } & & \multicolumn{2}{|c|}{$\begin{array}{c}\text { Unstandardized } \\
\text { coefficients }\end{array}$} & \multirow{2}{*}{$\begin{array}{c}\begin{array}{c}\text { Standardized } \\
\text { coefficients }\end{array} \\
\text { Beta }\end{array}$} & \multirow[b]{2}{*}{$\mathrm{t}$} & \multirow[b]{2}{*}{ Sig. } & \multicolumn{2}{|c|}{ Collinearity statistics } \\
\hline & & $\beta$ & Std. error & & & & Tolerance & VIF \\
\hline \multirow{5}{*}{1} & (Constant) & -8.212 & 1.121 & & -7.326 & .000 & & \\
\hline & Depth & -.022 & .002 & -1.284 & -11.091 & .000 & .253 & 3.951 \\
\hline & UCS & .020 & .013 & .197 & 1.522 & .136 & .201 & 4.963 \\
\hline & $\mathrm{B}$ & 2.870 & .265 & .886 & 10.813 & .000 & .505 & 1.981 \\
\hline & $\mathrm{B} / \mathrm{H}$ & .399 & .334 & .075 & 1.196 & .239 & .854 & 1.171 \\
\hline
\end{tabular}

TABLE 10: SSE CoEFFICIENT FOR DEVELOPING MODEL. 
TABLE 11: DATASET FoR VALIDATION

\begin{tabular}{cccccccccccccrr}
\hline no & $\mathrm{D}$ & $\mathrm{W}$ & $\mathrm{B}$ & $\mathrm{H}$ & $\mathrm{W} / \mathrm{H}$ & $\mathrm{B} / \mathrm{W}$ & $\mathrm{B} / \mathrm{H}$ & $\mathrm{UCS}$ & $\mathrm{PL}$ & $\mathrm{H} / 250$ & $\mathrm{PS}$ & $\begin{array}{r}\text { FoS } \\
\text { FoS-PCA } \\
\text { based }\end{array}$ & $\begin{array}{r}\text { FoS-SSE } \\
\text { based }\end{array}$ \\
\hline 1 & 70 & 26.0 & 3.6 & 1.8 & 14.44 & 0.1 & 2.0 & 40 & 9.1 & 0.007 & 22.24 & 2.44 & 2.298272817 & 2.174 \\
2 & 65 & 26.0 & 3.7 & 1.9 & 13.68 & 0.1 & 1.9 & 40 & 8.0 & 0.008 & 21.31 & 2.65 & 2.750875653 & 2.396 \\
3 & 60 & 26.0 & 3.7 & 2 & 13.00 & 0.1 & 1.9 & 42 & 7.1 & 0.008 & 20.93 & 2.96 & 3.234523767 & 2.66515 \\
4 & 65 & 26.0 & 3.6 & 2 & 13.00 & 0.1 & 1.8 & 43 & 8.5 & 0.008 & 21.14 & 2.49 & 2.536280487 & 2.2682 \\
5 & 65 & 26.0 & 3.8 & 2 & 13.33 & 0.1 & 1.9 & 38 & 6.9 & 0.008 & 20.39 & 2.95 & 3.231710854 & 2.791538462 \\
6 & 65 & 26.0 & 3.9 & 1.9 & 13.68 & 0.2 & 2.1 & 48 & 6.3 & 0.008 & 23.02 & 3.67 & 3.91094204 & 3.326 \\
7 & 65 & 26.0 & 4.2 & 1.9 & 14.05 & 0.2 & 2.3 & 41 & 4.8 & 0.007 & 21.96 & 4.61 & 4.565266925 & 4.131837838 \\
8 & 70 & 26.0 & 4.8 & 2.1 & 12.38 & 0.2 & 2.3 & 29 & 3.1 & 0.008 & 17.47 & 5.59 & 4.9357878 & 5.516 \\
9 & 75 & 26.0 & 4.8 & 2.1 & 12.38 & 0.2 & 2.3 & 27 & 3.4 & 0.008 & 16.95 & 5.06 & 4.753885309 & 5.356 \\
10 & 75 & 26.0 & 4.6 & 2.1 & 12.38 & 0.2 & 2.2 & 26 & 3.9 & 0.008 & 16.75 & 4.27 & 4.410291553 & 4.724 \\
11 & 55 & 26.0 & 4.2 & 2.1 & 12.38 & 0.2 & 2.0 & 30 & 4.0 & 0.008 & 17.68 & 4.39 & 4.422489523 & 4.03 \\
12 & 55 & 26.0 & 3.6 & 1.8 & 14.86 & 0.1 & 2.1 & 54 & 7.2 & 0.007 & 25.94 & 3.62 & 3.767611878 & 2.8168 \\
13 & 60 & 26.0 & 3.6 & 1.8 & 14.86 & 0.1 & 2.1 & 28 & 7.8 & 0.007 & 20.09 & 2.57 & 2.650603469 & 2.1768 \\
14 & 60 & 26.0 & 3.7 & 1.8 & 14.86 & 0.1 & 2.1 & 20 & 7.1 & 0.007 & 18.30 & 2.59 & 2.810743197 & 2.3246 \\
15 & 55 & 26.0 & 4.1 & 1.8 & 14.44 & 0.2 & 2.3 & 21 & 4.4 & 0.007 & 18.22 & 4.13 & 4.210575737 & 3.681833333 \\
16 & 55 & 26.0 & 4.2 & 1.9 & 13.68 & 0.2 & 2.2 & 30 & 4.0 & 0.008 & 19.27 & 4.78 & 4.582572121 & 4.12 \\
17 & 55 & 26.0 & 3.6 & 2 & 13.00 & 0.1 & 1.8 & 33 & 7.2 & 0.008 & 18.93 & 2.64 & 2.892736741 & 2.2782 \\
18 & 65 & 26.0 & 3.6 & 2 & 13.00 & 0.1 & 1.8 & 32 & 8.5 & 0.008 & 18.83 & 2.22 & 2.223874449 & 2.0482 \\
\hline
\end{tabular}

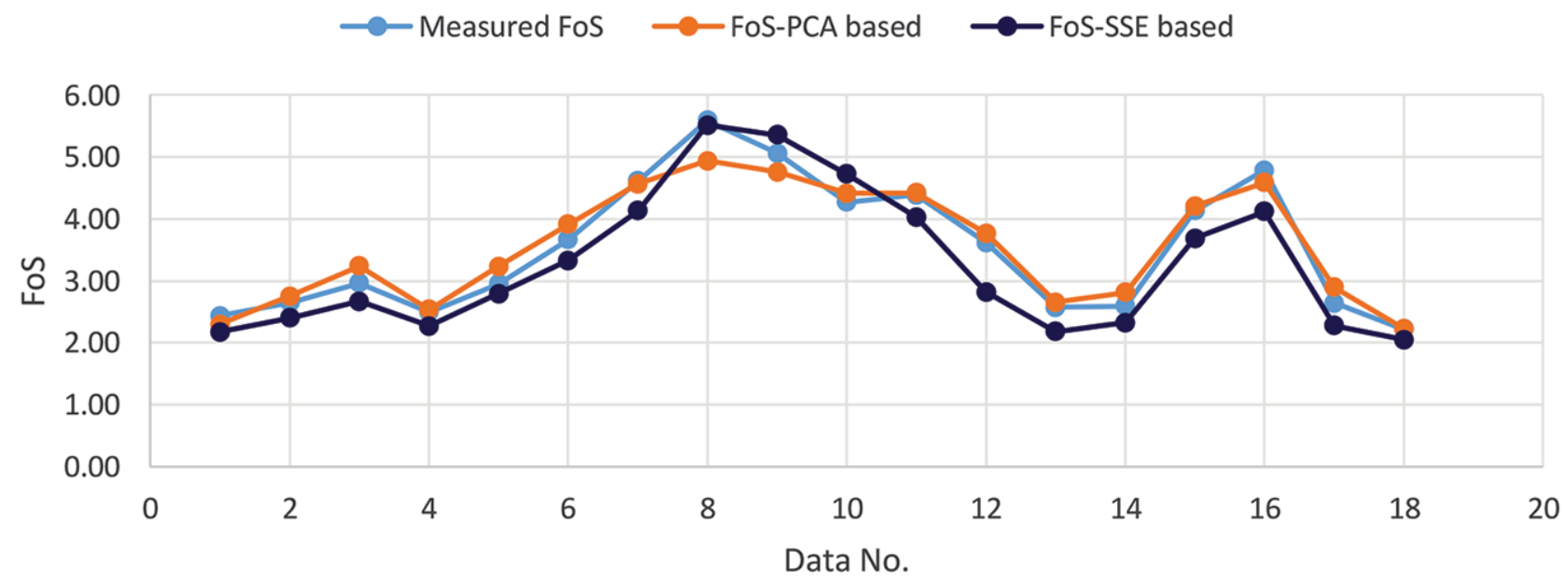

Fig.1: Validation of measured FoS with proposed models

On validation of the proposed model, it is found that the both PCA and SSE models have shown the approximately exact values of FoS, which is shown in Fig.1. By Fig.1, it is evident that the all the three lines are having similar trend of increasing and decreasing along with almost equal values, but it is interesting to evident that the values derived by PCA model as indicated in eq. 6 have nearer values with measured FoS, in comparison with SSE model. It indicates the better statistical assurance of PCA model in prediction of FoS.

\subsection{Conclusion}

The PCA technique has selected four important parameters affecting FoS, namely PL, H, PS and B/H. On the other hand,
SSE technique has also selected four important but different parameters than PCA which include D, B/H, B and UCS. The value of $\mathrm{R}^{2}$ for PCA was 0.86 and for SSE 0.84 , together with the root mean square values were 0.112 and 0.123 for PCA and SSE respectively. It is found that the PCA has better ability to predict the model for factor of safety. Further, the validation was performed on the proposed model by PCA and SSE, it is found by validation that we can express a higher level of statistical assurance on the proposed models.

\section{ABBREVIATIONS}

Principal component analysis PCA Sum of square error SSE 


$\begin{array}{ll}\text { Factor of Safety } & \text { FoS } \\ \text { Pillar load } & \text { PL } \\ \text { Pillar strength } & \text { PS } \\ \text { Uniaxial compressive strength } & \text { UCS } \\ \text { Pillar height } & \text { H } \\ \text { Pillar width } & \text { W } \\ \text { Gallery width } & \text { B } \\ \text { Depth cover } & \text { D } \\ \text { Multi-variant linear regression } & \text { MLR } \\ \text { Multi-Collinearity } & \text { MC }\end{array}$

\subsection{References}

1. Najafi M, Jalali SE, Bafghi AY, Sereshki F. (2011): Prediction of the confidence interval for stability analysis of chain pillars in coal mines. Safety science, Jun 1; 49(5):651-7.

2. Salamon MD (1970): Stability, instability and design of pillar workings. In International journal of rock mechanics and mining sciences \& geomechanics abstracts, Nov 1, Vol.7, No.6, pp. 613-631). Pergamon.

3. Tesarik DR, Seymour JB, Yanske TR. (2009): Long-term stability of a backfilled room-and-pillar test section at the Buick Mine, Missouri, USA. International Journal of Rock Mechanics and Mining Sciences. Oct 1;46(7):1182-96.

4. Brady BH, Brown ET. (1993): Rock mechanics: for underground mining. Springer science \& business media.

5. Lunder PJ. Hard rock pillar strength estimation an applied empirical approach (Doctoral dissertation, University of British Columbia).

6. Deng J, Yue ZQ, Tham LG, Zhu HH. (2003): Pillar design by combining finite element methods, neural networks and reliability: a case study of the Feng Huangshan copper mine, China. International Journal of Rock Mechanics and Mining Sciences. Jun 1;40(4):585-99.

7. Mortazavi A, Hassani FP, Shabani M. (2009): A numerical investigation of rock pillar failure mechanism in underground openings. Computers and Geotechnics. Jun 1; 36(5):691-7.

8. York G. (1998): Numerical modelling of the yielding of a stabilizing pillar/foundation system and a new design consideration for stabilizing pillar foundations. Journal of the Southern African Institute of Mining and Metallurgy. Oct 1; 98(6):281-97.

9. Hustrulid WA. (1976): A review of coal pillar strength formulas. Rock Mechanics. Jul 1; 8(2):115-45.

10. Jawed M, Sinha RK, Sengupta S. (2013): Chronological development in coal pillar design for bord and pillar workings: a critical appraisal. Journal of Geology and Mining Research. Jan 31; 5(1):1-1.
11. Martin CD, Maybee WG. (2000): The strength of hardrock pillars. International Journal of Rock Mechanics and Mining Sciences. Dec 1;37(8):1239-46.

12. Zhou J, Li XB, Shi XZ, Wei W, Wu BB. (2011): Predicting pillar stability for underground mine using Fisher discriminant analysis and SVM methods. Transactions of the Nonferrous Metals Society of China. Dec 1; 21(12):2734-43.

13. Ghasemi E, Kalhori H, Bagherpour R. (2017): Stability assessment of hard rock pillars using two intelligent classification techniques: A comparative study. Tunnelling and Underground Space Technology. Sep 1; 68:32-7.

14. Wattimena RK. (2014): Predicting the stability of hard rock pillars using multinomial logistic regression. International journal of rock mechanics and mining sciences (1997); 71:33-40.

15. Shnorhokian S, Mitri HS, Moreau-Verlaan L. (2015): Stability assessment of stope sequence scenarios in a diminishing ore pillar. International Journal of Rock Mechanics and Mining Sciences. Feb.1; 74:103-18.

16. Cauvin M, Verdel T, Salmon R. (2009): Modeling uncertainties in mining pillar stability analysis. Risk Analysis: An International Journal. Oct; 29(10):137180.

17. Griffiths DV, Fenton GA. (2004): Probabilistic slope stability analysis by finite elements. Journal of geotechnical and geo environmental engineering. May; 130(5):507-18.

18. Zhou J, Li X, Mitri HS. (2015): Comparative performance of six supervised learning methods for the development of models of hard rock pillar stability prediction. Natural Hazards. Oct, 1;79(1):291-316.

19. Kumar Brijesh, Sharma SK, Singh GSP. (2019): Enhanceddd prediction of hard rock pillars stability using fuzzy rough feature selectionfollowed by random forest. Journal of Mines, Metals \& Fuels. Nov, Vol.67, No.11.

20. Qi C, Fourie A, Ma G, Tang X, Du X. (2018): Comparative study of hybrid artificial intelligence approaches for predicting hangingwall stability. Journal of Computing in Civil Engineering. Mar 1; 32(2): 04017086.

21. Qi C, Tang X. (2018): Slope stability prediction using integrated metaheuristic and machine learning approaches: a comparative study. Computers \& Industrial Engineering. Apr 1; 118:112-22.

22. Esterhuizen GS, Dolinar DR, Ellenberger JL. (2011): Pillar strength in underground stone mines in the United States. International Journal of Rock Mechanics and Mining Sciences. Jan 1;48(1):42-50.

(Continued on page 108) 